\title{
The effect of ice-sheet thickness change on the accumulation history inferred from GISP2 layer thicknesses
}

\author{
NAdine N. Gutler, C. F. Raymond, E. D. WAdDington, \\ Geophysics Program AK-50, University of Washington, Seattle, WA 98195, U.S.A. \\ D. A. MEESE, \\ Snow and Ice Branch, U.S. Army Cold Research and Engineering Laboratory, Hanover, NH 03755, U.S.A. \\ R. B. AlLEY \\ Earth System Science Center and Department of Geosciences, The Pennsylvania State University, University Park, PA 16802, U.S.A.
}

\begin{abstract}
Net accumulation rates at the Greenland summit have been inferred using layer-thickness data from the GISP2 ice core with corrections for strain using a non-linear, one-dimensional flow model of an ice sheet. The flow model accounts for thickness changes in ice-sheet in response to mass-balance variations. The model is used to investigate how net accumulation-rate changes affect the time evolution of: (1) the ice-sheet thickness, (2) the vertical strain rate, and (3) the corresponding internal annual-layer structure. The model, parameterized to fit the present net accumulation rate and thickness of the Greenland ice-sheet summit, has a characteristic time constant for adjustment to accumulation-rate changes of about $6000 \mathrm{a}$ and yields an ice sheet $200-400 \mathrm{~m}$ thinner than its present thickness during the last glacial period.

Accumulation-rate histories inferred from GISP2 layer-thickness data using both a constant- and a variable-thickness model are compared. The variable-thickness model predicts accumulation rates about $25 \%$ lower than the constant-thickness model. Our results also indicate that high-frequency changes in accumulation rates (i.e. after the Younger Dryas event) are consistent with earlier analyses. However, sensitivity tests indicate that the accumulation-rate history cannot be precisely determined. Our analysis defines an envelope of likely accumulation histories bounded above by the accumulation history inferred by the constant-thickness model. Predictions become increasingly uncertain for old ice because of (1) intrinsic difficulties associated with this inverse problem, and (2) decreased accuracy of the data.
\end{abstract}

\section{INTRODUCTION}

Information about net accumulation in polar regions may be preserved in layers found in ice sheets. Sources of information include ${ }^{10} \mathrm{Be}$ (Raisbeck and Yiou, 1985), dated volcanic-debris and bomb-fallout layers and the thickness of annual ice layers (Paterson and Waddington, 1984; Reeh, 1990). Dust and other atmospheric constituents are mixed with the precipitation that falls on the icesheet surface. When firn compacts to ice, annual variations in these quantities are preserved in the ice, allowing annual layers to be identified. A detailed, continuous record of annual layer thicknesses near the Greenland summit has been obtained from the GISP2 ice core to $50000 \mathrm{BP}$ (Meese and others, 1994). Long-term average layer thicknesses for ice older than $50000 \mathrm{BP}$ can be determined from a depth-age scale based on the Vostok ice-core time scale and sea-sediment records (Bender and others, 1994). From this combined layer-thickness record, it is possible to obtain the most detailed, long-term history of accumulation over central Greenland to date.

The thickness of a given annual layer in an ice sheet is determined by the net annual accumulation at the time of deposition and the amount of strain the layer has experienced from ice flow. The strain-rate pattern in an ice sheet at a given time is in turn determined by the geometry and rheological properties of the ice sheet. Models that have been used to infer accumulation rates from layer thicknesses (e.g. Reeh, 1989; Alley and others, 1993; Dahl-Jensen and others, 1993) assume that the ice sheet maintains a constant thickness over time because the non-linear nature of ice flow makes the ice-sheet thickness rather insensitive to changes in the mass balance (Paterson, 1981, p. 157). Alley and others (1993) used this method to analyze the GISP2 layer-thickness record back to $17000 \mathrm{BP}$. In this paper, we examine the effect of ice-sheet thickness changes on ice flow and the layerthickness pattern.

We have developed a non-linear, one-dimensional model to investigate the evolution of ice-sheet thickness, 
the vertical strain rate and the annual layer thicknesses in response to changing accumulation rates. The model has three key assumptions:

(i) The rate of change in ice-sheet thickness can be determined from the accumulation rate and vertical velocity.

(ii) As it responds to changes in accumulation, the ice sheet evolves through a series of profiles that correspond to steady-state shapes.

(iii) The shape of the depth variation in vertical strain rate is constant over time.

We infer an accumulation history for GISP2 from layerthickness data using this variable-thickness model.

\section{THEORY}

Consider the behavior of a large ice sheet at some time. $t$, with center thickness $H$ at $x=0$ and $h$ at $x \neq 0$, with an accumulation rate, $b$, and with ice moving vertically downward and horizontally with velocity components $v$ and $u$ (Fig. 1). We assume that the surface and bed slope near the summit are essentially flat so that $\left|u \frac{\partial h}{\partial x}\right| \ll v$. Assumption (i) above can be stated as:

$$
\frac{\mathrm{d} H}{\mathrm{~d} t}=b-v .
$$

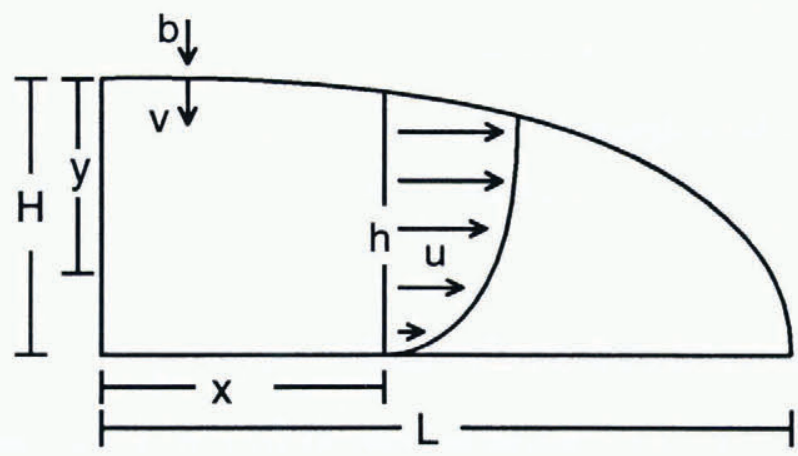

Fig. 1. Profile of a simple ice sheel. Horizontal and vertical velocity components are represented by $u$ and $v$, respectively. In steady state, the accumulation rate, $b$, is independent of position, $x$, and equal to the surface vertical velocity, $v(h)$.

According to this expression of mass conservation, if the accumulation rate increases/decreases with respect to a steady-state value, then the ice sheet gets thicker/thinner.

To relate the geometry of the ice sheet to the surface vertical velocity, we consider the configuration of a twodimensional ice sheet. Based on the standard assumptions (a) that the ice sheet is frozen to its bed, (b) that shear stress $\tau_{x y}$ increases linearly with depth from 0 at the surface to $\tau_{\mathrm{b}}$ at the bed, (c) that the surface slope is small, and (d) that there are no horizontal stress gradients, then

$$
\tau_{x y}=\tau_{\mathrm{b}} \frac{y}{h} \text { and } \tau_{b}=\rho g h \frac{\partial h}{\partial x} .
$$

In addition, we assume that ice deforms according to Glen's flow law so that $\frac{\partial u}{\partial y}=2 A \tau_{x y}^{n}$, that $n=3$, and that the temperature and structure of the ice are such that the flow-law parameter, $A$, is independent of depth, $y$. With these assumptions, the depth-averaged horizontal velocity $\bar{u}$ is given by

$$
\bar{u}=\frac{2 A}{n+2} h \tau_{\mathrm{b}}^{n} .
$$

If we further assume that local variations in the shape of the ice-sheet surface profile (caused by transient flow effects) diffuse away quickly so that the shape of the ice sheet is smooth and the surface vertical velocity, $v(h)=v(H)$, is independent of position, $x$, then at any given instant, continuity of ice mass requires that

$$
v(h) x=\bar{u} h
$$

where $h$ is the thickness at $x$, and $\bar{u}$ is the depth-averaged horizontal velocity.

Combining Equations (3) and (4), and integrating from the edge where $h=0$ to the divide where $h=H$, yields an ice-sheet shape. If the ice sheet were in steady state with $v(h)=b$, then this shape would correspond to the steady-state profile derived by Vialov and described in Paterson (1981, p. 154 157). Our more general approach allows the ice sheet to change its thickness while maintaining a shape at any given instant that corresponds to a Vialov steady-state profile associated with $v(h)$ rather than $b$ (assumption (ii) above).

At the divide $(x=0)$, this shape gives the following relationship between $H$, the ice-sheet thickness at the divide, $L$, the half-width, and $v(H)$, the surface vertical velocity:

$$
H=f(n, A) L^{1 / 2} v(H)^{(1 / 2 n+2)}
$$

where $f$ depends on $n$ and $A$. For $n=3$, the $1 / 8$ power in Equation (5) shows that the thickness is relatively insensitive to changes in mass balance. If the thickness changes, the velocity also changes so as to oppose the thickness change.

Since the thickness of the Greenland ice sheet at the GISP2 site is essentially the same as the thickness at the divide, we only need to calculate $H(t)$, and the problem is reduced to one dimension. If we further assume that the margins are fixed $(L=$ constant), that the flow law parameter, $A$, does not change over time, and that the present geometry at GISP2 represents a steady-state geometry, then $f$ is a constant which can be determined by parameterizing Equation (5) for the present conditions at GISP2. The ice thickness there is about $3025 \mathrm{~m}$ ice equivalent), and the surface vertical velocity can be taken to be equal to the present accumulation rate of $0.24 \mathrm{~m} \mathrm{a}^{-1}$ ice equivalent (Bolzan and Strobel, 1994).

Equation (5) describes how the surface vertical velocity is related to the ice-sheet thickness. To describe the strain rate at depth, we apply assumption (iii) above: the nondimensional shape of a given vertical velocity profile that is characteristic of off-divide ice flank flow) is timeindependent. This assumption is based on theoretical and experimental arguments showing that the shapes of velocity profiles in ice sheets with uniform rheological properties are insensitive to small changes in surface geometry Raymond, 1983; Hindmarsh, 1990). The velocity at depth is then scaled to the vertical velocity at the surface according to a non-dimensional shape, $\phi\left(\frac{y}{H}\right)$, so that 


$$
v(y, t)=v(H, t) \phi\left(\frac{y}{H}\right) .
$$

Equations (1), (5) and (6) together describe the effect of accumulation-rate changes on the ice-sheet thickness and the vertical strain-rate distribution.

However, since the flow law in real ice sheets is not uniform or time-independent, the vertical velocity profile does not actually maintain a given shape over time. To estimate the error from assumption (iii), we compare the model results using three distinct, non-dimensionalized vertical velocity profiles: one generated by a finite-element model of the GRIP GISP2 flowline Schott and others, 1992 ; one calculated analytically for a flow enhancement ice "softness" caused by impurities and/or development of a $c$-axis fabric) and temperature distribution characteristic of interglacial conditions; and one calculated for an enhancement and temperature distribution characteristic of glacial conditions (Fig. 2). Details of these calculations are provided in a later section.

\section{NUMERICAL METHODS}

To run the model forward in time, we take a prescribed accumulation history and calculate a thickness change and a vertical velocity distribution at each $(50 \mathrm{a})$ time step. Horizons are tracked as they move deeper into the ice sheet. This forward model produces a layer-thickness pattern and an ice-sheet thickness history. The characteristic response time of a glacier or ice sheet to mass-balance changes should be on the order of $\mathrm{H} / \mathrm{b}$ (Jóhannesson and others, 1989), or about $10 \mathrm{ka}$ for GISP2. Our model, when tested with sinusoidally varying accumulation-rate histories, gives a response time with the correct magnitude, about $6 \mathrm{ka}$.

The inverse problem requires calculation of netaccumulation-rate and thickness histories given a laverthickness pattern such as the one from the GISP2 ice core.
Simply running the forward model backward and unstraining the layers at each time step is unstable. In the forward model, the thickness response to a mass-balance impulse decays exponentially with time. When the model is run backward, this response to mass balance is expressed as a growing exponential that leads to an unstable thickness prediction. To avoid this instability, we couple the forward and backward calculations and use an iterative method. We start with a constant-thickness history and calculate a corresponding accumulation history by unstraining the layers from the GISP2 core (moving backward in time). This accumulation history is used to calculate a new thickness history by running the model forward in time. This new thickness history is then used to calculate a new accumulation history from the GISP2 layers by running the model backward in time, and so on. We iterate until a consistent accumulation and thickness history is obtained (about five iterations). Figure 3 illustrates this coupled process. To summarize, model inputs and outputs are the following:

\section{Model inputs}

1. Annual layer thickness profile from GISP2.

2. Non-dimensional vertical velocity profile.

3. Reference conditions for thickness, half-width, and surface vertical velocity to define the parameter $f$ in Equation (5)).

4. Initial thickness history.

\section{Model outputs}

1. Accumulation history.

2. Thickness history.

\section{RESULTS AND DISCUSSION}

We applied this model to layer-thickness data from the GISP2 ice core. From 105000 to $50000 \mathrm{BP}$, the data are
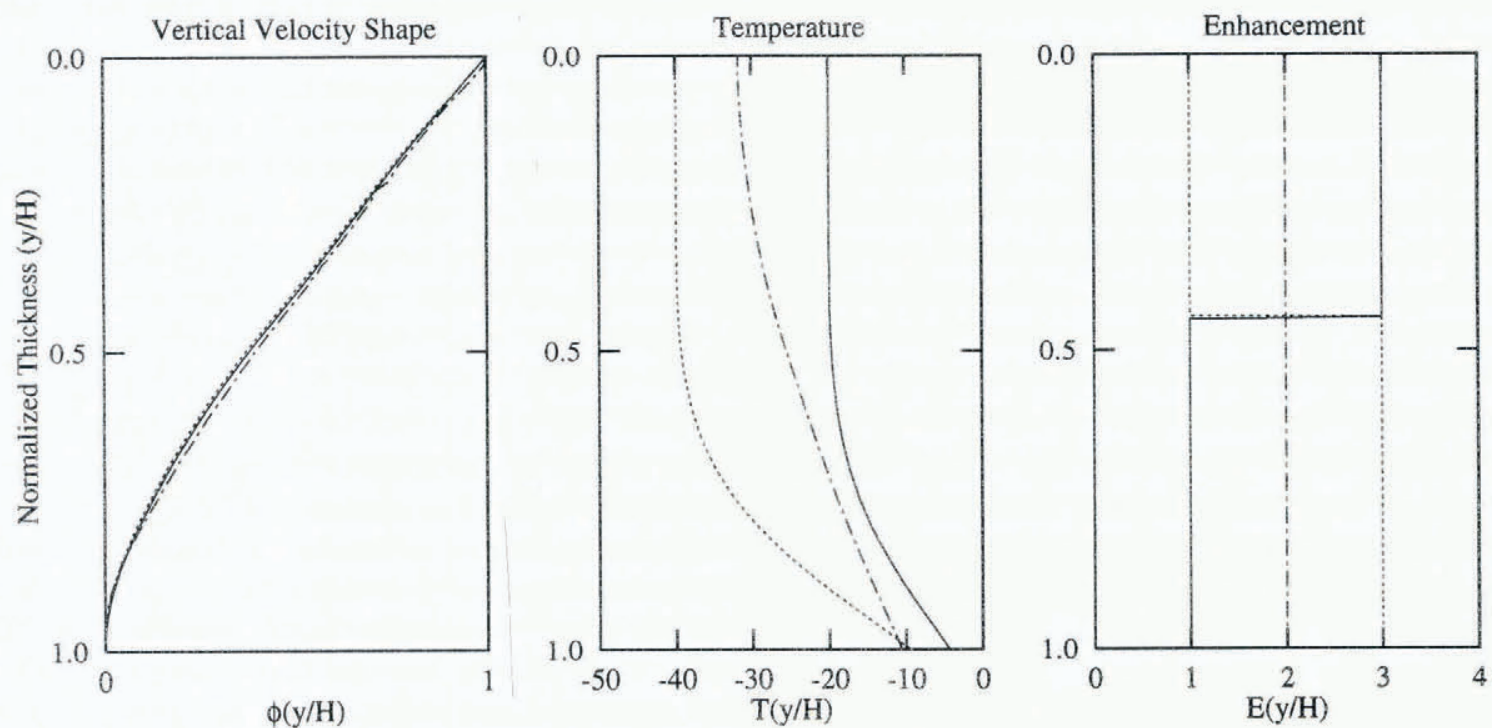

Fig. 2. Vertical velocity profile shapes used to lest sensitivity of model results to possible changes in the strain-rate pattern from temperature and flow enhancement from chemistry and fabric. Corresponding temperature and enhancement distributions used to calculate the velocity profiles are also shown. The dashed-dot line represents the finite-element calculation. The solid and dashed lines represent the velocity calculations for characteristic glacial and interglacial 


\section{Forward calculation for $\mathrm{H}(\mathrm{t})$ :}

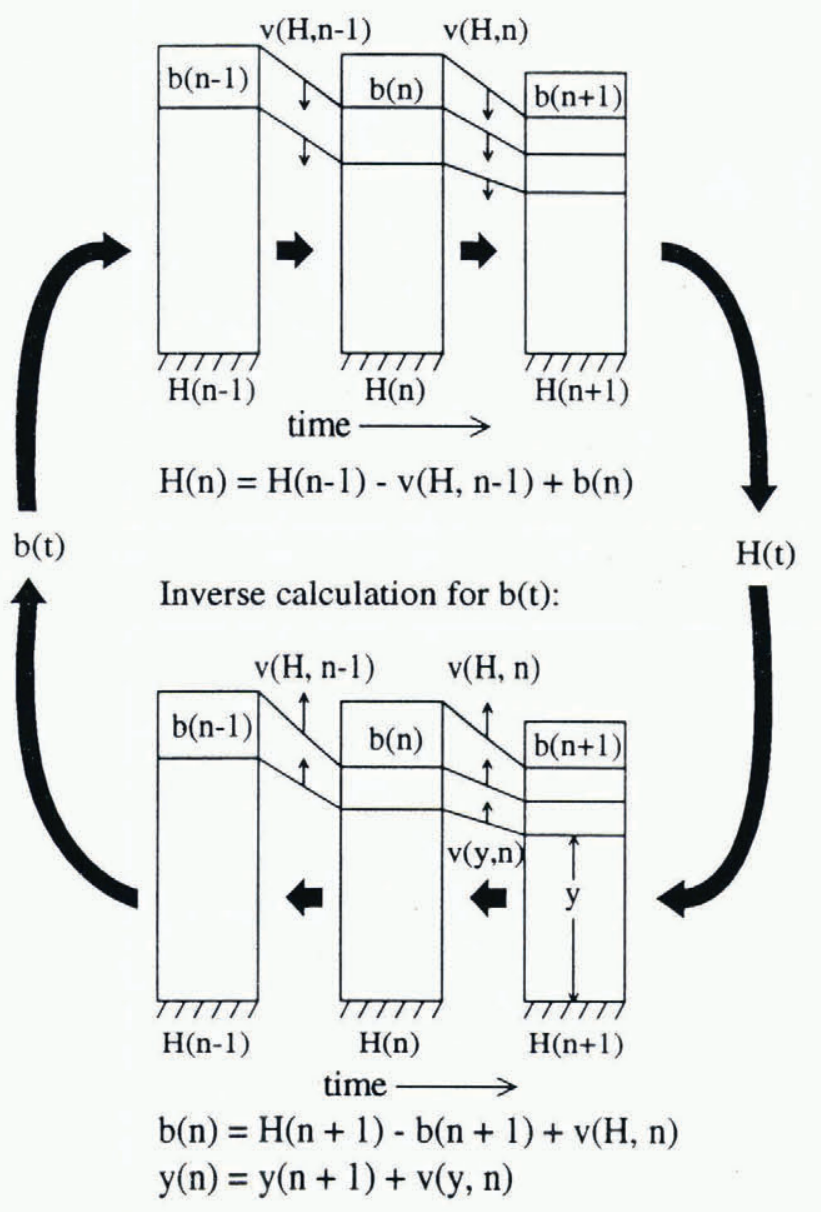

Fig. 3. Illustration of the iterative method used in the model. Each rectangular box represents the ice column. Representative interfaces are indicated by horizontal lines. Bold arrows indicate the direction of calculations, and $n$ indicates the time step. A prescribed thickness history, $H(t)$, with an assumed vertical velocity distribution, $v(y)$, is applied to the GISP2 layer-thickness data to calculate an accumulation-rate history, $b(t)$. This accumulation-rate hislory is then used to calculate a new thickness history. A consistent accumulation-rate and ice-thickness history is achieved after about five iterations.

based on a 12 point time-scale obtained from the Vostok time-scale and sea-sediment records Bender and others, 1994). More recently than $50000 \mathrm{BP}$, the data are based on the identification and counting of annual layers in the core (Meese and others, 1994). To reduce noise, these annual layer-thickness data were averaged over $2 \mathrm{~m}$.

The solid curve in Figure 4a shows the inferred accumulation rates after five iterations of the model. For this calculation we used the vertical velocity profile from a finite-element calculation along the GRIP-GISP2 flowline (Schott and others, 1992). The half-width $L$ was fixed at its present value of about $400 \mathrm{~km}$. The dotted curve in the figure is the accumulation-rate history inferred assuming no thickness change. To see the long timescale differences between the accumulation histories predicted by the constant-thickness model and the variable-thickness model, both curves shown in Figure $4 \mathrm{a}$ have been smoothed with a 500 a running average.
Consequently, the amplitude of very high-frequency vartiations in accumulation rate are somewhat reduced. The sharp peaks in both curves at about 55000, 81000 and $86000 \mathrm{BP}$ are caused by discontinuities in slope of the coarse depth-age curve prior to $50000 \mathrm{BP}$. The variablethickness model predicts accumulation rates about 20 $25 \%$ lower than the constant-thickness prediction for the pre-Holocene record. The variable-thickness model also preserves the high-frequency variations in accumulation rates. The corresponding ice-sheet thickness histories are shown in Figure $4 b$.

\section{Validity and uniqueness}

There are two main sources of uncertainty that become increasingly significant for older ice: (1) over-simplifications in the theory, and (2) errors in the data. First, uncertainties in vertical strain rates become large for deeper and older ice. Secondly, the thickness prediction for the oldest times is suspect because the model ice sheet does not know its accumulation or thickness prior to the time the model begins ( $105000 \mathrm{BP})$. Since it takes several time constants $6 \mathrm{ka}$ ) for the ice-sheet thickness to forget its initial conditions, results prior to about $90000 \mathrm{BP}$ depend on the initial conditions and are not shown in Figure 4. Thirdly, errors in the relative position of measured layer horizons would lead to some artificially thick layers and some corresponding artificially thin layers. The fractional error in these layer thicknesses would be preserved in the model and would lead to higher-amplitude noise in the inferred accumulation history for the older and deeper ice. However, the long-term average would be preserved. Since errors in the vertical strain rate and the data are probably smaller near the upper part of the ice core, results for the most recent part of the record are the most reliable.

It is not immediately clear that the thickness and accumulation histories recovered by this model are unique. The constant-thickness calculation produces one accumulation history that is consistent with the layerthickness pattern at GISP2. Our new method, which employs different physical assumptions, produces another accumulation and thickness history that is consistent with the layer-thickness pattern. However, is it plausible that, given the same physical assumptions, this model might give two or more distinct solutions for thickness and accumulation histories that are consistent with the GISP2 layer-thickness data? To test this question, we created synthetic-layer profiles using the forward method with a prescribed periodic (100 ka) accumulation history. We then attempted to reconstruct the accumulation history by our iterative backward calculation. The model recovered the original accumulation history almost exactly. In another test, white noise of a specified maximum amplitude was added to a synthetic-layer thickness profile. The inferred accumulation from the backward iterative calculation preserved the fractional errors introduced by the noise; it did not amplify them. We conclude that high-frequency variations in the inferred accumulation history are recovered with an accuracy controlled by the fractional error of the measured layer thicknesses. We are confident that the 

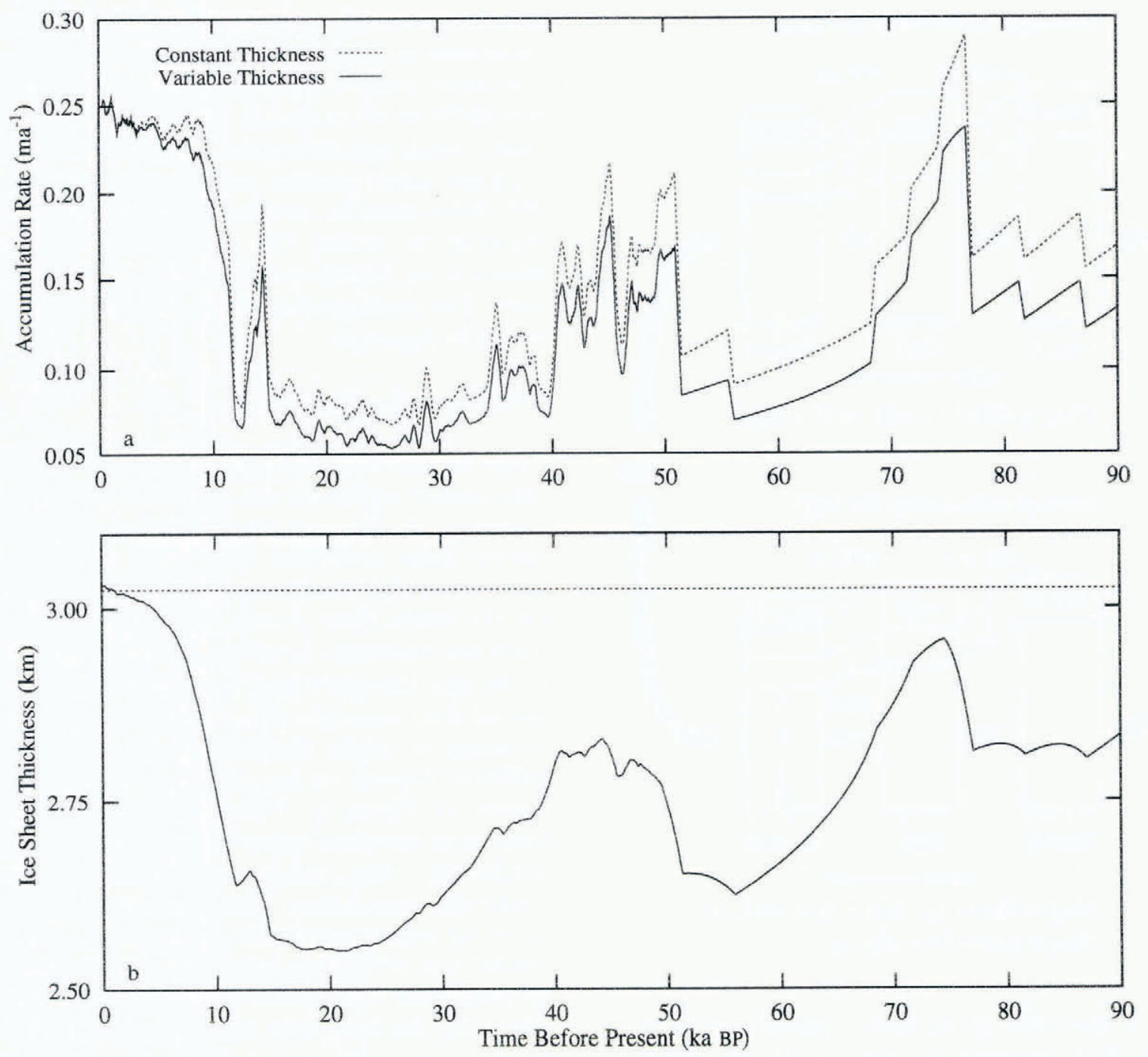

Fig. 4. (a) Accumulation-rate history in mice a ' for GISP2 using this model (solid line) compared to the inferred accumulation history inferred assuming constant thickness (dashed line). These calculations assume the vertical velocity shape given by a finite-element model (Schott and others, 1992) and a fixed half-width, L. To show long-time scale differences, both curves have been smoothed with a 500 a running average. The sharp peaks in accumulation rates at about 55000,81000 and $86000 \mathrm{BP}$ are caused by discontinuities in the slope of the coarse depth-age curve prior to $50000 \mathrm{BP}$. These accumulation-rate histories define the envelope of most plausible accumulation histories at GISP2. (b) Corresponding ice-sheet thickness histories. Maximum thickness reduction for the variable-thickness calculation is about $450 \mathrm{~m}$.

solutions calculated by this model are stable and unique given our assumptions.

\section{Comparison with other models}

Our calculations, assuming a fixed half-width $L$, predict a maximum thickness reduction of about $450 \mathrm{~m}$ for the last glacial cycle. More complex models of the Greenland ice sheet (Huybrechts and others, 1991; Letréguilly and others, 1991) predict more modest values for thickness change. Letréguilly and others (1991) predict a maximum thickness reduction of about $200 \mathrm{~m}$ at the summit, using an accumulation calculated from a temperature history derived from oxygen-isotope measurements at the Pakitsoq margin. Those measurements predict higher temperatures and therefore more precipitation during the last glacial cycle $\left(\sim 0.14 \mathrm{ma} \mathrm{a}^{-1}\right)$ than the GISP2 layer data seem to indicate. This difference in accumulation history affects the thickness-change prediction. When we used the same accumulation rates as Letréguilly and others (1991), our model predicted a thickness reduction of $250 \mathrm{~m}$, in reasonable agreement with their result. These more complex models also assumed as we did that the margins of the ice sheet were pinned at their present position over time. The discrepancy in the predicted thickness change, then, arises from differences in the accumulation history used in the models rather than fundamental differences in model characteristics and parameterization.

\section{The effect of a non-steady vertical velocity profile}

The calculation shown in Figure 4a assumes that the shape of the vertical velocity profile is not altered by evolving temperature and ice-softness (enhancement) distributions in the ice column. We attempted to determine the sensitivity of the inferred accumulation rates to changes in the vertical velocity profile shape by running the model with various distinct velocity profiles. 
One profile (used in Figure 4a) was generated by a finiteelement calculation of ice flow near the Greenland summit (Schott and others, 1992). Two additional profiles were calculated analytically from simple models of a two-dimensional ice slab. An enhancement factor, $E(y)$, was used to include the effect of flow-law variations caused by the development of a crystal fabric or changes in impurity concentrations. This factor was taken to be 3 for softer glacial ice and 1 for interglacial ice Paterson, 1991). One of the two additional velocity profiles was calculated for a temperature and enhancement-factor distribution, $T(y)$ and $E(y)$, characteristic of interglacial conditions, and the other for a temperature and fabric distribution characteristic of glacial conditions (Fig. 3). The horizontal velocity profile, $u(y)$, can be obtained by integrating the flow-law equation

$$
\frac{\partial u}{\partial y}=2 E(y) A(y)(\rho g y \sin \alpha)^{n}
$$

where $y=0$ at the surface and $y=H$ at the bed. The flow-law parameter $A(y)=A_{0} \exp \left(-\frac{Q}{R T(y)}\right)$, where $Q$ is the activation energy, $R$ is the gas constant, $n=3$, and $\alpha$ is the surface slope (Paterson, 1981). The horizontal velocity, $u(x, y)$, can be approximated as:

$$
u(x, y)=\beta(x) \xi\left(\frac{y}{H}\right) .
$$

Vertical velocity, $v(y)$, can in turn be obtained by continuity:

$$
\frac{\partial u}{\partial x}=\frac{-\partial v}{\partial y} .
$$

The two parameters, $\mathrm{d} \beta / \mathrm{d} x$ and the constant of integration, are determined by the boundary conditions: $v(0)=0$ and $v(H)=b$. Figure 2 shows the calculated vertical velocity profile shapes and the corresponding temperature and enhancement distributions.

Predicted mass-balance histories calculated using these various vertical velocity profile shapes vary by about $10 \%$. All calculations are within the envelope shown in Figure $4 \mathrm{a}$.

\section{The effect of changing ice-sheet margins}

We assumed that the ice-sheet margins were fixed in most of our calculations. However, the margins of the Greenland ice sheet are not fixed; the half-width may have expanded by about $25-100 \mathrm{~km}$ from the present position during the last glacial cycle Reeh 1984; Anandakrishnan and others, 1994). Expanding the margins would decrease the slope of the ice-sheet profile and allow the ice sheet to thicken, even during periods of low accumulation. Assuming that the margin-position, $L(t)$, and massbalance changes are roughly $180^{\circ}$ out of phase, then a changing margin position would make the ice-sheet thickness less sensitive to mass-balance changes and lead to inferred accumulation rates more like those inferred with the constant-thickness assumption. To determine the sensitivity of model results to changing margin position, the model was modified to account for a crude margin- position history. Although it is most likely that the margin expansion for Greenland was asymmetric during the last glacial period Reeh 1984; Anandakrishnan and others 1994), we assumed a symmetric change in margin position, roughly $180^{\circ}$ out of phase with the long-term temperature change. We specified $L(t)$ to be constant at $450 \mathrm{~km}$ during the last glacial period, decreasing linearly from 12000 to $5000 \mathrm{BP}$ to the approximate present length of $400 \mathrm{~km}$, and constant to the present. This calculation predicts a thickness change of about $250 \mathrm{~m}$ for the Last Glacial Maximum, and the accumulation history inferred is about 10-15\% lower than the constant-thickness prediction. When a margin expansion of $100 \mathrm{~km}$ is prescribed, the inferred accumulation history closely matches the prediction assuming constant thickness, and the ice-sheet thickness change ranges from +300 to $100 \mathrm{~m}$ during the last glacial period.

\section{The effect of flow description}

As a final sensitivity test, we used the model to infer an accumulation history for an ice sheet where deformation is concentrated at the base, such that the horizontal velocity, $u(y)$, is independent of depth and proportional to the base stress to a power $m=2$ (Nye, 1959). This leads to a thickness profile that is more sensitive to changes in mass balance: $H \propto b^{1 / 5}$. This increased sensitivity predicts a larger ice-sheet thicknessreduction $(700 \mathrm{~m})$, lower accumulation rates during the last glacial period (about 30-35\% lower than the constant-thickness prediction) and a more gradual increase in accumulation rates since the Younger Dryas. However, since it is believed that the Greenland ice sheet is frozen to its bed and does not flow by basal sliding (Firestone and others, 1990 ), we consider this accumulation history to be outside the envelope of plausible histories for the GISP2 site.

\section{CONCLUSIONS}

A model that accounts for the effect of ice-sheet thickness change on the vertical straining of ice layers predicts an accumulation history from GISP2 layer-thickness data that is different from that predicted assuming constant ice-sheet thickness. Various tests show that the accumulation history is sensitive to other factors including: (1) the shape of the vertical velocity profile which is affected by the temperature and structure of the ice, (2) the change in margin position over time, and (3) the description of ice flow (e.g. Vialov vs Nye models). These tests are summarized in Table 1. Hence, it is not possible to identify a "true" accumulation history for GISP2 with this model, but an envelope of plausible accumulation histories can be defined (Fig. 4a). The upper bound for this envelope is given by the inferred accumulation rates assuming constant ice-sheet thickness. The lower bound is given by the variable-thickness model assuming (a) that ice flows by internal deformation rather than basal sliding, (b) that the ice-sheet margins remain fixed, and (c) that a vertical velocity shape is given by a finite-element calculation (Schott and others, 1992). Since the most realistic scenario for the Greenland ice sheet involves an increased half-width during glacial periods, and since the inferred accumulation history considering this 

Extreme thickness
change

$\mathrm{m}$
Change in b( $t$ ) from constantthickness prediction

\section{Constant thickness}

Vialov flow: internal deformation Margins fixed

Margin expansion: $50 \mathrm{~km}$ Margin expansion: $100 \mathrm{~km}$ Nye flow: basal sliding (Margins fixed)

$$
\text { Finite element }
$$

Finite element Interglacial calculation

Glacial calculation

Finite element

Finite element
0

$-450$

$-450$

$-450$

-250 to +100

-100 to +300
0
$20-25$

$10-15$

$<5$

Finite element

change in margin position lies near the upper extreme of the envelope, the envelope of most plausible accumulation histories for the Greenland GISP2 site is probably narrower than the envelope shown in Figure 4 a by about $10 \%$.

The inferred accumulation history for the oldest and deepest ice is uncertain for a variety of reasons. Specifically, the accumulation-rate history inferred from deep ice layers is especially sensitive to changes in the vertical strain-rate pattern. This simple theory may not adequately describe the vertical strain rate for deep ice. Also, decreased accuracy of the data for older ice contributes to errors in the inferred accumulation rate. To further constrain the accumulation history near the Greenland summit, the next step would be to compare -these results to the accumulation history inferred from the GRIP core, located about $30 \mathrm{~km}$ east of GISP2 (DahlJensen and others, 1993). Perhaps such a comparison would yield information about accumulation variability near the Summit region over time and provide clues about past changes in global circulation patterns.

\section{ACKNOWLEDGEMENTS}

This research was supported by grant No. OPP-9123660 from the U.S. National Science Foundation. We thank the 109th Air National Guard, the Polar Ice Coring Office and the GISP2 Science Management Office for logistical support. We also thank K. M. Cuffey and A. M. Eades for helpful suggestions to improve the manuscript.

\section{REFERENCES}

Alley, R. B. and 10 others. 1993. Abrupt increase in Greenland snow accumulation at the end of the Younger Dryas event. Nalure, $362(6420), 527-529$.

Anandakrishnan, S., R.B. Alley and E. D. Waddington. 1994. Sensitivity of the ice-divide position in Greenland to climate change. Geophys. Res. Lell., $21(6), 441-444$.

Bender, M. and 6 others. 1994. Climate connections between Greenland and Antarctica during the last 100,000 years. Nature, 372 6507), 663-666.
Bolzan, J. F, and M. Strobel. 1994. Accumulation-rate variations around Summit, Greenland. J. Glaciol., $40(134), 56-66$.

Dahl-Jensen, D., S.J. Johnsen, C. U. Hammer, H. B. Clausen and J. Jouzel. 1993. Past accumulation rates derived from observed annual layers in the GRIP ice core from Summit, central Greenland. In Peltier, W. R., ed. Ice in the climate system. Berlin, Springer-Verlag, 517-532.

Firestone, J., E. Waddington and J. Cunningham. 1990. The potential for basal melting under Summit. Greenland. J. Glaciol., 36 123), 163-168.

Hindmarsh, R.C.A. 1990. Time-scales and degrees of freedom operating in the evolution of continental ice-sheets. Trans. R. Soc. Edinburgh: Earth Sci. 81, 371-384.

Huybrechts, P., A. Letréguilly and N. Reeh. 1991. The Greenland ice sheet and greenhouse warming. Palaeogeogr., Palaeoclimatol., Palaeoecol.. 89 4), 399-412.

Jóhannesson, T., C. F. Raymond and E. Waddington. 1989. Time-scale for adjustment of glaciers to changes in mass balance. $\mathcal{f}$. Glaciol., 35 (121), 355369.

Letréguilly, A., N. Reeh and P. Huybrechts. 1991. The Greenland ice sheet through the last glacial-interglacial cycle. Palaeogeogr., Palaeoclimatol., Palaeoecol., 90 4), 385-394.

Meese, D. A. and 8 others. 1994. Preliminary depth-age scale of the GISP2 ice core. CRREL Spec. Rep. 94-1.

Nye, J.F. 1959. The motion of ice sheets and glaciers. J. Glaciol., 3 (26), $493-507$.

Paterson, W.S. B. 1981. The physics of glaciers. Second edition. Oxford, etc., Pergamon Press.

Paterson, W. S. B. 1991. Why ice-age ice is sometimes "soft". Cold Reg. Sci. Technol., 20 1), $75-98$.

Paterson, W.S. B. and E. D. Waddington. 1984. Past precipitation rates derived from ice core measurements. Rev. Geophys. Space Phys., 22 (2), $123-130$.

Raisbeck, G. M. and F. Yiou. 1985. ${ }^{10} \mathrm{Be}$ in polar ice and atmospheres. Ann. Glaciol., 7, 138-140.

Raymond, C.F. 1983. Deformation in the vicinity of ice divides. J. Glaciol., 29 (103), 357-373.

Reeh, N. 1984. Reconstruction of the glacial ice covers of Greenland and the Canadian Arctic islands by three-dimensional, perfectly plastic ice-sheet modelling. Ann. Glaciol., 5, 115-121.

Reeh, N. 1989. Dating by ice flow modeling: a useful tool or an exercise in applied mathematics? In Oeschger, H. and C. C. Langway, Jr, eds. The environmental record in glaciers and ice sheets. Chichester, etc., John Wiley and Sons, 141-159.

Reeh, N. 1990. Past changes in precipitation rate and ice thickness as derived from age-depth profiles in ice-sheets; application to Greenland and Canadian Arctic ice core records. In Bleil, U. and J. Thiede, eds. Geological history of the polar oceans: Arctic versus Antarctic. Dordrecht, Kluwer Academic Publishers, 255-271.

Schott, C., E. D. Waddington and C.F. Raymond. 1992. Predicted time-scales for GISP2 and GRIP boreholes at Summit, Greenland. $\mathcal{Y}$. Glaciol., 38 (128), 162-168. 